\title{
28. Additive manufacturing and its impact on the supply chain
}

\author{
Henk Zijm, Nils Knofius, Matthieu van der Heijden
}

\begin{abstract}
Additive Manufacturing (AM) is rapidly gaining interest as a highly innovative manufacturing technology, having many advantages over more conventional manufacturing methods. These advantages include the ability to produce very complex structures that are relatively easily customized to specific user requirements. The fact that AM services become affordable for small companies or even for consumers offers possibilities for decentralized manufacturing, downstream in the supply chain. In addition, AM allows for high degrees of flexibility, both in product design and manufacturing, as a result of using smart CAD systems that may be based on accurate scanning technologies. The ability to work with low setup times and costs, and to largely eliminate work in progress inventories while maintaining a high degree of supply chain responsiveness makes AM a promising alternative for low-volume, high-value items. In this chapter, we outline the basics of AM technologies, after which we discuss at a more advanced level its impact on the supply chain. Next, we turn to spare parts delivery in after-sales service supply chains; these slow moving parts are often mentioned as ideal candidates for AM. In a state-of-the-art report, we provide a methodology for the identification of spare parts that may appear promising candidates for the application of AM. We conclude with a field study conducted at a service provider in the aerospace industry.
\end{abstract}

\subsection{Additive Manufacturing (basics)}

Additive Manufacturing (AM) is a technology that enables the production of complex geometries and near-net shape components. Its name stems from the fact that it builds a component, part or product from raw materials layer by layer (additively). Conventional machining methods such as cutting, milling, drilling or lathing, remove material and are therefore classified as subtractive manufacturing. Although only recently known to the broader public, the first AM technology was already commercialized in the late 1980 's, when it was used as a technique for rapid prototyping, called stereolithography. In this technology, a vat with a vertically moving platform is filled with a photocurable liquid polymer. With the platform in upper position, a laser focuses an ultraviolet beam on the upper surface layer, curing that part of the photopolymer to create a solid body. Next, the platform is lowered a bit and the cured polymer is covered with another layer of liquid polymer, after which the sequence is repeated (Kalpakjian, 1992). By varying the shape of each new polymer layer, complex geometries can be built up with stereolithography.

\subsubsection{Basic technologies, characteristics and fields of application}

Today, there exists quite a variety of AM technologies, of which the most important ones are Selective Laser Sintering (SLS) and Selective Laser Melting (SLM), Electronic Beam Melting (EBM), Digital Light Processing (DLP) and Fused Deposition Modeling (FDM). For a detailed exposé of these different technologies we refer to Gibson et al. (2015); here it suffices to say that they differ widely in the amount and type of materials used, in speed and accuracy, and in their domains of application. In the following, we present a more general overview of AM technologies to lay the foundation for the discussion of supply chain matters later. References given in the further readings section at the end of this chapter may serve as a starting point for a more comprehensive study on the differences of the various AM technologies. Note that the term 3D printing is often used as a synonym for additive manufacturing. In the sequel we will also use the terms interchangeably since they both refer to layer based manufacturing techniques. Sometimes, the term Additive Manufacturing is used for parts in a production context that need to satisfy tight specifications, whereas 3D printing often refers to the fabrication of less critical consumer products. 
For most AM technologies, the process starts with a user-defined 3D CAD file of a component or product. Specific AM software then will be used to cut the 3D CAD into slices that are fed into an AM machine to "build-up" the component layer upon layer as shown in Figure 28.1. An increasing variety of raw materials becomes available, including ceramic powder, metal or even glass, next to polymers. The CAD file may be generated from a design process, but may also result from a 3D scan of an existing object or body. Because of this, design changes are easily incorporated. The thickness of the layers may be in the order of microns; naturally, the thinner the layer, the more detail and accuracy can be achieved.

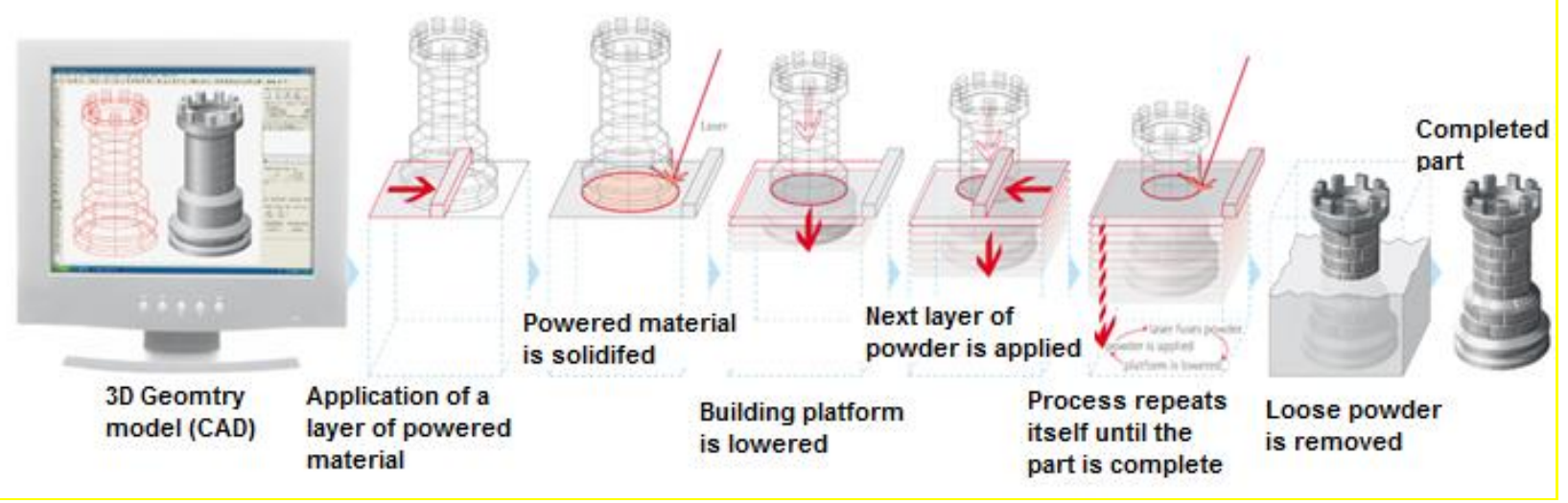

Figure 28.1. The principle of Additive Manufacturing. Source: EOS (2017).

The unique production process of AM technologies has several implications for future manufacturing. Let us therefore look at some potential benefits that derive from the basic properties of AM technologies.

- $\quad$ The design freedom to produce complex and tailored parts

The design freedom of AM technologies is certainly one of the main benefits. Design compromises to improve the manufacturability are significantly less limiting with AM technologies than with conventional methods and thus facilitate a more usage-driven design. Complex structures can be built with an optimal balance between strength and material usage that is not feasible with subtractive technologies. Consequences can be observed in the aerospace industry where lightweight designs, that are producible with AM only, lead to significant fuel savings. Figure 28.2 exemplifies this opportunity and shows the conventional (a) and the AM design (b) of a hinge bracket that is used in aircrafts. Overall, the AM-enabled topology optimization lead to a weight reduction of $25 \%$.

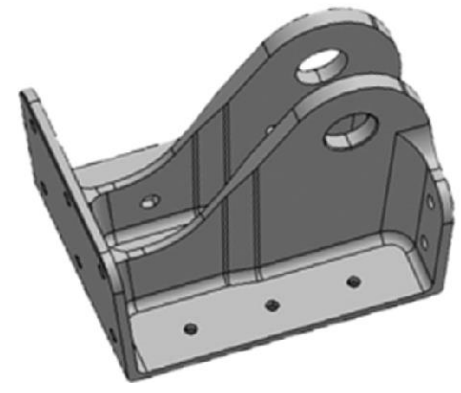

(a)

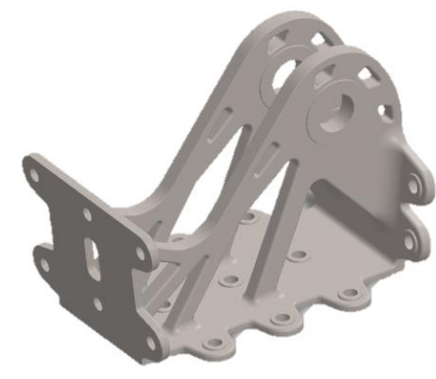

(b)

Figure 28.2. Conventional (a) and AM (b) design for a hinge bracket used in aircrafts (Knofius et al. 2017) 
Other common examples for design improvements concern heat exchangers or valves where thermal control or flow resistance are improved. However, not only for individual parts AM's design freedom holds significant implications. Complex parts that previously were assembled from various lower level parts and components, may become producible as an one piece part. Joints or screws that previously were required for the assembly become superfluous. Hence, not only the weight reduces, but potential failure modes like cracks or erosion can be avoided. Supply chain configurations may simplify significantly because the number of distinct parts that need to be sourced, tracked and inspected decreases. We will pay further attention to the implications of the latter aspect in Section 28.2.1.

- $\quad$ Reduced material waste and energy consumption from an operational perspective

The reduction of materials usage is obvious in additive processes. Note that the materials are fed to an AM machine in different states than those used in subtractive processes (e.g. granular or fluid). Combined with the more uniform requirement for raw materials, this characteristic may compensate for the often energy-intensive production process. Indirect effects caused by lower weight or optimized part properties may even further reduce the energy consumption. Hence, from a lifecycle perspective, the energy balance of 3D-printed parts may well turn out to be positive.

- A high level of customization

The possibility to design products according to customer specifications and to manufacture them on-demand, using only basic materials, is entirely due to the fact that both the design and the manufacturing process are highly digitalized. Tooling or product-dependent setup process are (usually) not required, making AM an extremely flexible technology. Thus, for instance, design changes or product changeovers are easily realized while the production process remains unaltered. As we will discuss later, especially for medical and dental applications where customer-specific solutions are paramount, AM transformed entire supply chains.

\section{- $\quad$ Faster time to market}

The fact that design and manufacturing process are so closely intertwined, together with the fact that the product is built up in one piece from raw materials only, eliminated a number of steps in assembled processes. Hence, AM may significantly reduce the time to market which may secure a competitive advantage. Risks associated with market failure decrease, given low setup and tooling costs. Accordingly, it is likely that AM may support a more aggressive market strategy. In addition, fast design changes based on market feedback become possible and thus give rise to more aggressive business strategies.

Despite the potential of AM technologies, it would be incorrect to assume that AM is about to replace conventional production methods. It appears more likely that AM technologies complement rather than replace conventional production methods. The subsequent discussion should clarify today's shortcomings of AM technologies, and the trade-offs involved when compared to conventional manufacturing methods.

Most prominent is the misperception that an AM process alone produces industrial grade parts. Instead, major postprocessing steps are often required for achieving sufficient quality. Support structures may need to be removed, or treatments may be required to improve material properties. Furthermore, process variability, inherent to today's AM methods, often invokes extensive quality controls that increase production lead times and costs. In some fields, like the aerospace sector, process variability complicates the economic certification of safety critical parts. Additional concerns are raised by the digital nature of AM methods. While increasing flexibility, businesses worry about the protection of intellectual property rights and liability. The latter is clarified by a simple example. Consider an 
innovative company who offers 3D-designs of his products for sale. After a customer printed this product (maybe with slight alterations to the design) and it fails, who is hold responsible for a failure: the company, the printing service provider, the AM equipment manufacturer? Today, no standardized legal agreements are in place, which creates uncertainty about promising new business models. Finally, available materials, size limitations and short development cycles of AM equipment may hamper the breakthrough of AM technologies in several fields. For example, additive manufacturing of electronic parts is still a major challenge.

But it is not only due to these shortcomings why companies may decide against AM methods and use conventional manufacturing methods instead. This becomes clear if we compare AM methods with injection molding. Injection molding, which is itself a production technique capable to produce parts in one piece from raw materials, is quite the opposite of AM in terms of flexibility. Based upon a product specification, special molds have to be designed and fabricated at high costs. Though, products manufactured with injection molding are relatively cheap for high volumes, and the actual production time of a single product may be a matter of seconds. This makes injection molding suitable for mass production. On the other hand, AM is not suitable at all for mass production for the following reasons. A print of large and complex product geometries may take several hours, while often being highly energy-intensive. In combination with low economies of scale, this causes relatively high marginal production costs. However, small-batch or one-of-a-kind production often profit from the low setup and tooling cost of AM and thus are considered as the main benefiters of AM technologies.

Subsequently, we will detail our discussion on application areas of AM. We will have a look the rapidly growing number of industries and sectors, typically those where advantages like high customization, light weight and short time to market count most. The strategic research agenda of the Additive Manufacturing Platform (cf. AM Platform, 2014) mentions a number of key domains which have adopted AM as a key technology, including:

- Medical and dental applications: in particular titanium alloys have been extensively used as powder material for fabricating orthopedic/orthodontic implants. Other applications can be found in e.g. the hearing aid industry, which has made the transition to almost $100 \%$ AM. The key driver for these type of applications is typically the ability to provide customized solutions for an affordable price.

- The Aerospace industry, which develops devices based on again titanium and nickel alloys, next to polymers. Today, main business driver are weight and attributed fuel savings. Projects like NASA's 'zero gravity' 3D printer meant to produce spare parts in the International Space Station (ISS) show interest to further expand AM's application area, cf. TechCrunch (2016). Future scenarios where, for instance, downtime of airplanes are reduced with printed spare parts are likely.

- Automotive, which is the second largest sector adopting AM. In this sector, the design flexibility is one of the most important arguments to move to $A M$, next to the fast realization of prototyped or low-volume car parts. Experimentation with large scale prints may motivate further applications and indicate the interest to secure weight and thus fuel savings very much like in the aerospace sector, cf. Ford (2017).

- Consumer products: to date the largest but also the most diverse sector that has embraced AM technologies. Mostly, the technology is still used for prototyping but a quickly growing number of endusers has discovered AM to deliver highly personalized devices and products, ranging from toys and busts to home furnishings to fashion items (robes, shoes).

Other fields of application include industrial machinery, the military domain and architecture (prototyping). An overview of the most important applications is found in Figure 28.3, based upon Wohlers (2014). 


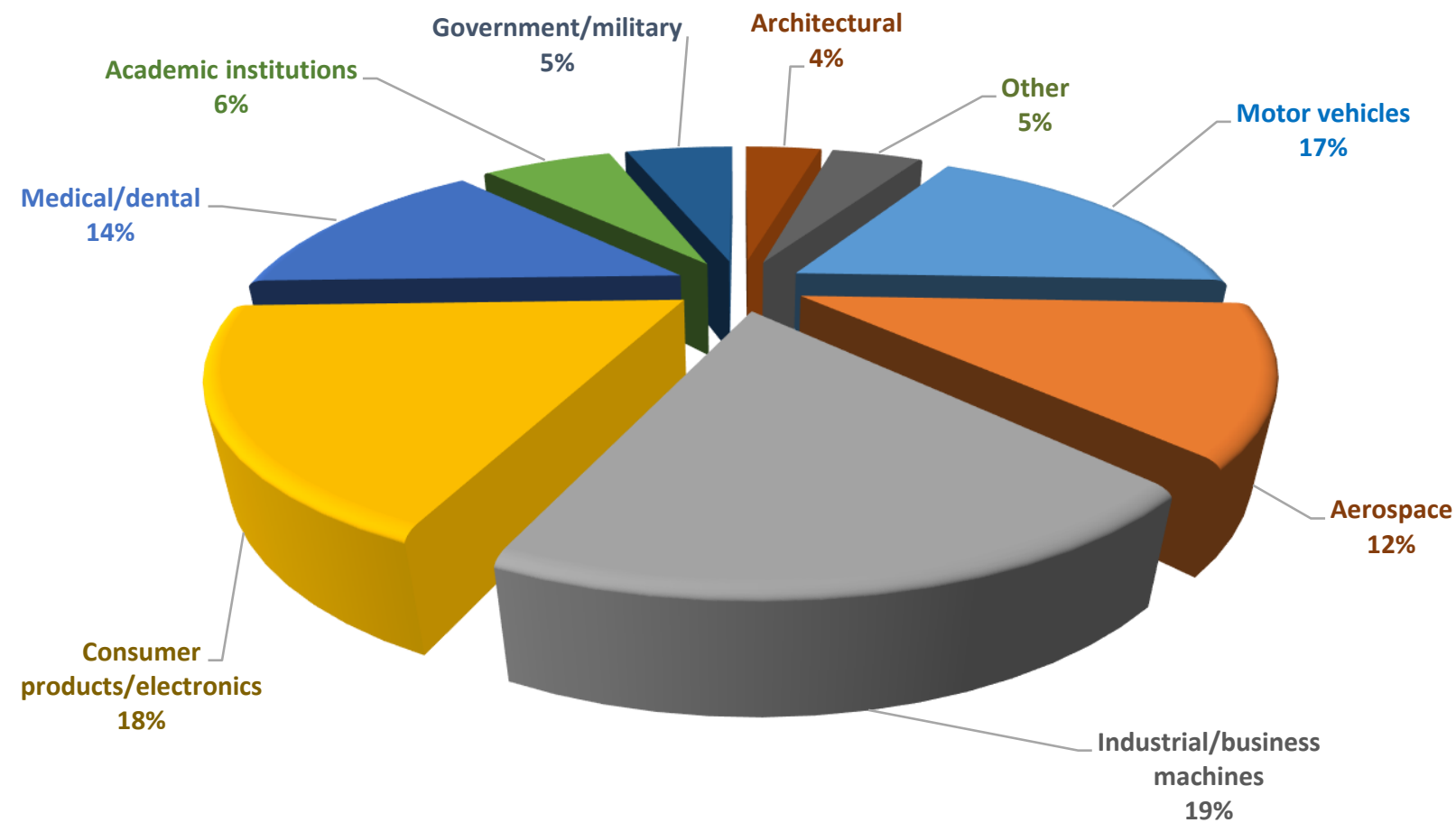

Figure 28.3 Percentage of Industrial and Public Sectors using Additive Manufacturing (Wohlers, 2014)

In a Harvard Business Review publication, McCue (2015) reports that 30\% of the Top 300 largest global enterprises are now using or evaluating the potential of AM. Some of the companies that are already exploiting AM technology are: General Electric (jet engines, medical devices), Lockheed Martin, Airbus and Boeing (aerospace and defense), and Aurora Flight Sciences (Unmanned Aerial Vehicles), cf. D’Aveni (2015). In summary, AM has quickly gained a firm position in the manufacturing arena. Based upon the observed drop of the cost of AM systems with $50 \%$ in the last decade (Thomas, 2016) and a further expansion of the materials range, an increased penetration of the manufacturing arena is generally expected. Accordingly, forecasts of Siemens (2014), a multi-national conglomerate, predict an AM market growth of $300 \%$ within the next 10 years.

\subsubsection{Case Study: Additive manufacturing for customized mountain bikes}

(based on a case study published by Renishaw (2016))

A mountain bike is a sports bicycle designed for off-road cycling. In principle, they are similar to other bikes but they should withstand heavy use in rough terrain. For that reason, they typically include a front or full suspension, broad tires, durable wheels, powerful brakes and low gear ratios to enable climbing steep hills. High end mountain bikes often have a frame made from carbon-fiber reinforced resins, which are molded. Because of the molding process, the bikes are usually made only in a limited number of sizes whereas for sportsmen and -women it is extremely important to ride a bike that perfectly matches the body's measures and powers, in other words, that fits the individual rider.

Robot Bike Co. is a company that took up the challenge to make customized mountain bikes. To that end, they came up with a new design consisting of a series of carbon fiber-reinforced tubes that needed to be joined by titanium lugs to constitute the frame. The material titanium was chosen for the lugs because of 
its ability to carry high pressures while carbon fiber-reinforced tubes are both strong and light. The challenge is in the design of the titanium joints. The angles used in the joint, together with the lengths of the sections of tubing, should be unique to match the measures and wishes of the ultimate rider.

Robot Bike Co. sought cooperation with a few design companies to come up with an optimal design in terms of weight and material use, subject to stress and strain conditions and matching the individual customer's need. The result is a bespoke bike, consisting of a number of parts that are uniquely tuned to the specific customer. Advanced CAD and simulation tools were used to produce a parametric CAD engine for mountain bike design. Subsequently, Renishaw, a worldwide operating company with a reputed additive manufacturing center, took up the challenge to manufacture the titanium lugs. The production process starts with bespoke CAD geometries produced from bike design software on the Robot Bike Co. website, where customers can input the required body measurements. The geometries are next imported into Renishaw's build-preparation software, where the optimum orientation for each part is selected and the support structures required for a successful build are added. The eleven lugs required for each bike are grouped together, along with their supports, to be produced in a single build (cf. Figure 28.4). Upon completion, the build plate with the eleven parts attached is removed from the laser powder bed fusion system and heat treated. Then, the individual parts are separated from the plate and from each other. Some of the lugs require finish machining to produce precision bearing features. The production process is completed with inspection of each part on a co-ordinate measuring machine.

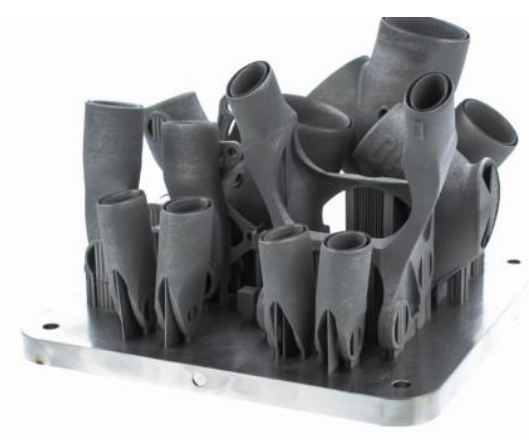

Figure 28.4. Titanium lugs with build plate, produced by additive manufacturing (Renishaw, 2016)

The frames assembled from the specialized carbon fiber-reinforced tubes and the titanium joints have passed a variety of tough quality and safety tests. As a result, Robot Bike Co. is now able to deliver high quality bespoke mountain bikes, thanks to the customization abilities of additive manufacturing technology.

\subsection{Additive manufacturing and supply chains (advanced)}

In this section, we systematically investigate the impact of AM on various aspects of the supply chain. Generally, a supply chain for conventional manufactured products is characterized by a number of functional areas (component manufacturing, final assembly, raw materials and component storage, distribution warehouses, and in general transport between any two facilities). Upon disposal by its user, the product may be returned and possibly its components can be re-used, see Figure 28.5 .

For the sake of a fair comparison, we consider the case of a product that is directly delivered from the distribution center to the end-user (no retail functions involved). Next, we systematically evaluate how the main characteristics of the supply chain will change, once the assembled product is replaced by a product manufactured using AM. We 
concentrate on typical operational characteristics, such as lead times, in process inventories, system responsiveness and supply chains costs.

\subsubsection{Impact of AM on the Supply Chain}

Already earlier, we noted that the design freedom that product developers experience is an attractive feature of AM technologies. At the same time, the manufacture of products is generally perceived to be quite costly, due to, for example, the high energy use of the AM process and the relatively long production time, cf. Section 28.1. But what we will see is that the consolidation of component functionalities into one piece in combination with decentralized manufacturing may compensate for these disadvantages. Here, with consolidation we indicate the redesign of an assembled part or product, such that its constituting components are replaced by fewer, but more complex components, which hence integrate various functionalities.

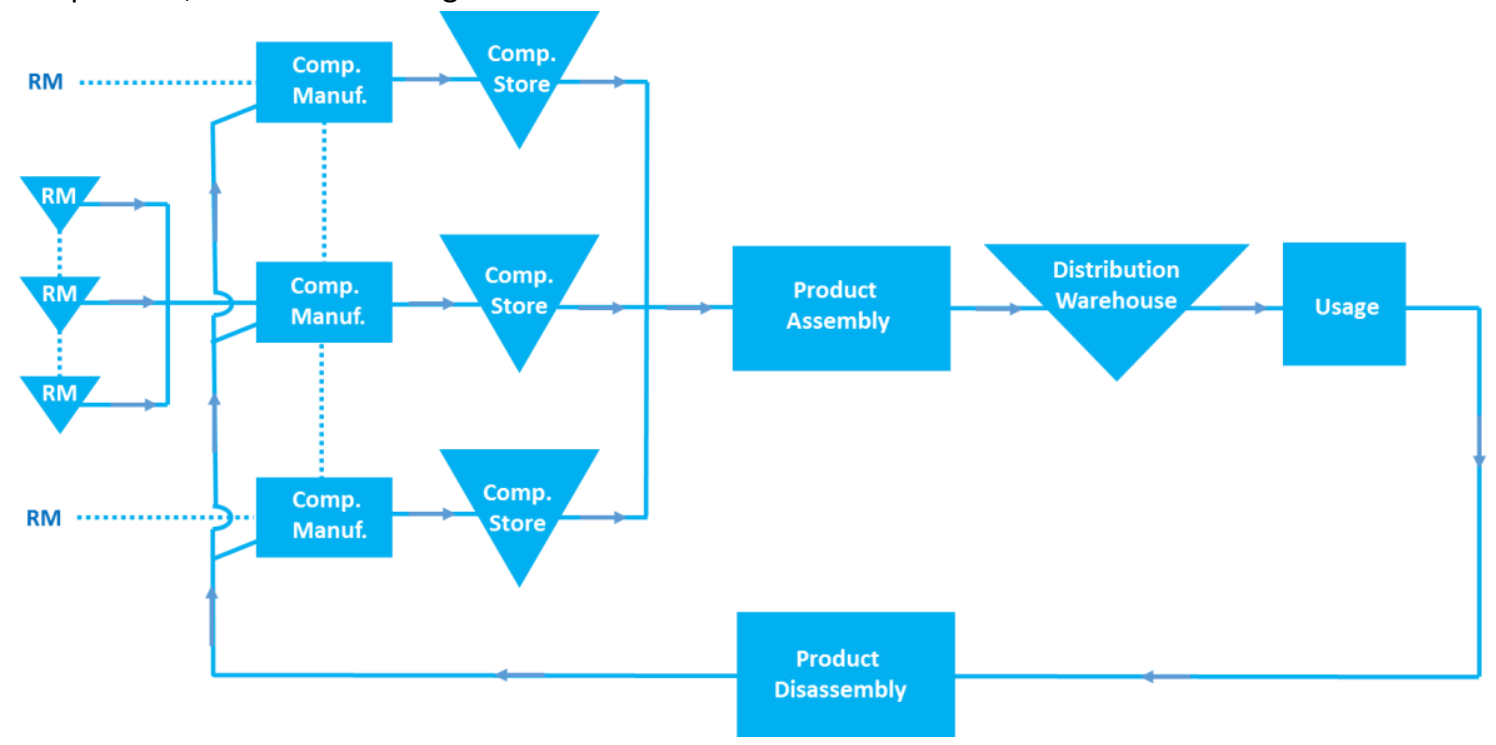

Figure 28.5. Supply chain for a customized product using conventional manufacturing (RM = Raw Materials)

\section{Supply Chain Structure}

Typically, in conventional manufacturing all components need to be available before assembly can start. If a number of components is skipped because their functionality is integrated in a 3D-printed part, the corresponding supply relations are no longer needed which reduces synchronization efforts. Consequently, the need for multi-level production planning decreases and thus lessens associated risks and costs.

\section{Supply Chain Inventories}

Consolidation of functions due to integration implies that raw materials are directly used in final product manufacturing. Consequently, downstream stocks are no longer needed. In particular for customized products, this may have far-reaching consequences. Today, customization is typically achieved with modular product designs, where customer requirements are satisfied by combining the right components in one final product. While a modular product design enables postponement of a desired product configuration, modularity comes with the sacrifice of often high inventories of many different components to achieve fast response times. With AM, component inventories may become (partially) avoidable due to the strong digitalization of the manufacturing process, cf. 
Section 28.1. Finally, raw material inventories reduce due to the fact that less material is wasted compared to subtractive manufacturing techniques.

\section{Decentralized manufacturing and transport times}

3D printing facilities can be rather modest and therefore lend themselves to decentralized manufacturing, even more if component stocks are limited (in case of many component stocks, centralized inventories that allow for pooling of stocks are more natural). Clearly, production close to customers may reduce final distribution and transportation time considerably. The fact that raw materials have to be supplied to these decentralized locations is not a serious problem since it concerns bulk transport of only a few basic materials. Growing numbers of printing farms, where service providers offer printing capacity on demand and location, exemplify the perceived value of this business model. The need for spare parts at remote locations as for example often encountered in the mining industry or during humanitarian missions may profit from decentralized manufacturing as well.

\section{Component Lead times}

Most components in a classical assembly process are ordered from external suppliers, but even if they are manufactured in a department of the same factory that delivers the final product, they have to be planned in advance, according to e.g. an MRP methodology (cf. Chapter 12). Typically, components are produced in batches for reasons of efficiency, blowing up lead times and inventories even further, while additional delay may occur due to queueing problems in case of limited machine capacity. Hence, consolidation using AM may lead to severe lead-time reductions in the overall supply chain.

\section{Customer responsiveness}

As mentioned earlier, in conventional manufacturing short customer response times are generally realized via high inventories of either final products or modules and components. Commonly this approach causes a significant amount of capital invested and hence diminish a company's liquidity. The opposite approach are less stocks but longer customer waiting times since specific components need to be ordered, which may reduce sales.

The flexibility and speed to setup or alter a production process with AM may provide an alternative. In particular, often investment in raw material stocks suffices in order to provide the required responsiveness. This implies a shift of the Customer Order Decoupling Point (or: push-pull boundary) upstream the supply chain (cf. Chapter 6). Reduced transport times, achieved by customer's proximity, also contribute to short customer response times.

\subsubsection{Costs and benefits of $A M$ in the supply chain}

As becomes clear from the discussion in the previous section, the ultimate decision to invest in AM depends on a careful trade-off between costs and benefits. AM may appear as an expensive process, but when expanding the view to its impact on a supply chain level, there are significant benefits in terms of inventory reduction (hence enhancing liquidity, i.e. freeing capital for investments), shorter lead and customer response times. From an sustainability point of view, the resulting picture is less clear; reduction of materials waste during production is obviously beneficial. On the contrary, the value of the product after discarding it is at least debatable, whereas for classically manufactured products, it may be feasible to reuse functioning components.

AM is a manufacturing technology that highly depends on digitalization, and therefore requires skills that are quite different from classical manufacturing. Typically, designers and software engineers are highly trained specialists, whereas the required amount of lower skilled labor at a machine operator level is less than in conventional manufacturing. As a result, the cost of manual labor as a percentage of the overall product price is rather low, which is an argument to locate the production processes in high wage countries, instead of transferring it to low wage countries. Indeed, observing that labor rates in China are now about five times as high as in 1990 (EPRS, 2014), quite 
many companies have decided to reshore the manufacturing of high-tech products back to Europe and the US. In addition, as we saw, decentralized production becomes attractive once a major part of the process is primarily software-based.

For the same reason, AM appears to be an excellent candidate for cloud manufacturing (cf. Chapter 6). Although the price of AM devices is sharply decreasing, the costs of high level professional equipment is still significant, in particular in view of the fact that most production concerns slow moving items while technology life cycles of AM equipment are short. However, the combination of product design flexibility, digital transfer of product data and the relatively stable (less varying) process characteristics makes it relatively simple to outsource the production process to specialized AM service providers. Indeed, the number of such providers is rapidly growing; they may offer not only manufacturing processes as such, but more and more also design support. There is no doubt that the combination of $A M$ and cloud manufacturing offers a fascinating outlook.

In the next section, we shift our focus to the implications of AM for the after-sales service logistics of expensive capital goods. In particular, we discuss how the associated low-volume, high value spare part business may change with the emergence of AM technologies.

\subsection{Additive manufacturing of spare parts (state-of-the-art)}

So far, we have discussed products intended to end users primarily. An important additional group are products that serve as parts in larger assets (machines, vehicles, aircraft or building constructions). Such parts may eventually malfunction or even completely fail, and then need to be either repaired or replaced. Since the costs of downtime of a capital asset may be high, often one chooses to limit downtime by replacing the malfunctioning part, and either disposing it or repairing it off-line. In any case, there should be spare parts available. As a result, one may observe high spare parts inventories (of many different items) to anticipate any possible failure, representing a significant investment. Typically, demand for spare parts is low (slow movers), as failures should not occur often for a welldesigned product. Hence, a lot of stock is actually tied up for low demand items.

\subsubsection{Specific opportunities of AM in after-sales service supply chains}

As discussed by Gibson et al. (2010), low volume spare parts are mostly produced on generic (i.e. non-dedicated) equipment (e.g. CNC workstations). The fact that they require a set-up time in addition to special tools and fixtures make their overall manufacturing costs relatively high. It seems then natural to think about 3D-printing these parts on demand as an alternative. Very much as for regular parts, it is likely that, as a consequence of 3D-printing, inventories decrease while the responsiveness can be maintained or even improved. Given the long turnaround times of slow moving parts, it is instructive to note that low inventories simultaneously reduce the risk of obsolescence, i.e. storing parts that in the end are not used at all anymore.

But there are more (unique) reasons why AM may qualify as great fit for the spare part business. Upstream in the supply chain it is not untypical that a supplier decides to discontinue the production of spare parts, for example because the low volumes are not commercially interesting anymore when compared to other opportunities. At best, the asset owner (or service provider) gets a chance to once purchase a final set of parts to cover possible demand during the entire remaining lifetime of its assets (cf. Behfard et al., 2016), but in any case it is clear that such a supply risk may in the short run cause severe problems. In such a case the possibility to print the part directly from raw materials, based upon a stored CAD file, presents a welcome alternative.

Also relevant for the spare parts business might be the option to repair parts with AM technology. Worn out parts that were previously discarded or expensive to repair may become repairable with AM and thus significantly reduce the maintenance cost of the capital good. The potential is demonstrated by means of a burner tip used in gas turbines 
at Siemens. Siemens (2014a) was able to reduce the repair lead time by $90 \%$ and the associated repair cost by $30 \%$. Figure 28.6 illustrates how a new burner tip is printed and afterwards attached to the burner.

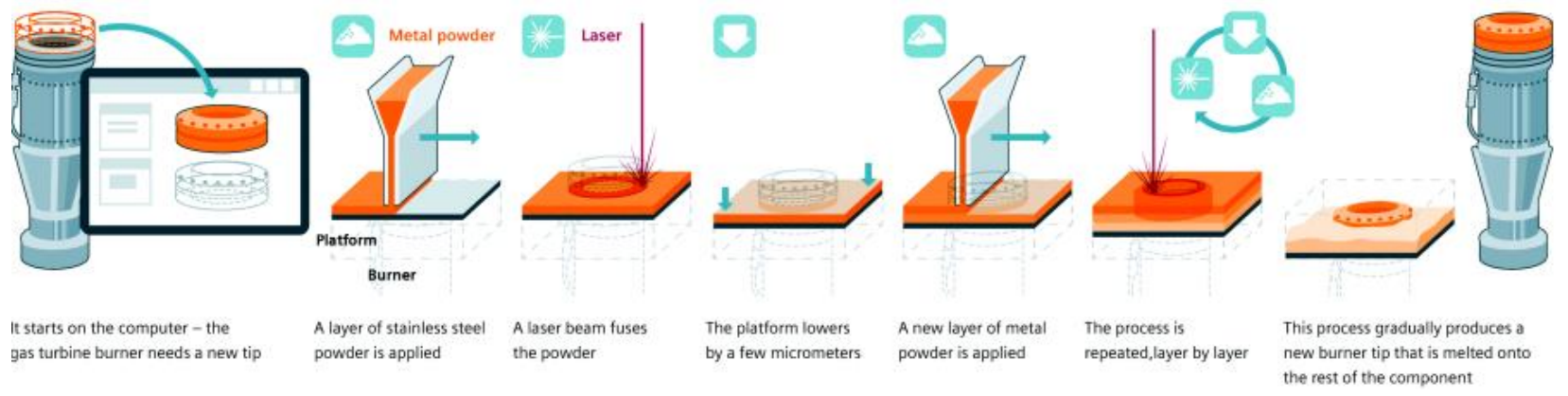

Figure 28.6. Repairing burner tip with Additive Manufacturing (Andersson et al., 2016)

And even if a conventionally manufactured spare part appears to be the technically and commercially best solution, it still may appear valuable to 3D-print a spare part as a temporary fix. That is, the printed part would bridge the period until the intended replaceable becomes available. Interesting for this application is that a temporary fix might even turn-out valuable if it yields lower performance rates. Preliminary results indicate that, in case the failure rate is ten times higher than for the conventional manufactured part, a temporary fix still may remain profitable (Knofius et al. 2017).

There are also arguments against the use of printed spare parts. Part characteristics may worsen significantly. For example, based on the process characteristics of AM, often unit cost and reliability of the AM part are inferior compared to the conventionally manufactured version. Also, conventional parts that are built up from components may be repaired by replacing only a malfunctioning component after which the part is re-assembled. A 3D-printed part on the other hand may have to be discarded as a whole, resulting in more waste while its replacement by a complete new part is definitely more costly than the replacement of a simple malfunctioning component or subcomponent in a conventionally manufactured part. Similarly, possible commonality effects are lost because of the higher customization of the consolidated part (Knofius et al., 2016a).

Overall, it should be clear that also for the spare part business a detailed assessment of the costs and benefits of applying AM are necessary. It appears certain, however, that AM technologies, with their unique characteristics, hold the opportunity to transform several fields of the spare part business in the near future. The described applications may lend themselves as valuable starting point to motivate the economic value. Subsequently, we discuss a more algorithmic approach for the selection of spare parts having item and supply chain characteristics suitable for AM as mentioned before.

\subsubsection{Selecting spare parts for 3D printing}

As explained in the previous section, spare parts used in capital assets seem to be potential candidates for AM, based on their relative low demand, their often high manufacturing costs, and their short customer order lead times. For many practitioners however, it is not clear how to identify the most promising spare parts. Overall, asset owners and service providers often deal with spare parts assortments easily exceeding hundreds of thousands of spare parts. Amid these circumstances, a manual assessment of each spare part appears virtually impossible. In this section, we describe a method which prioritizes spare parts according to their likelihood of being valuable for AM. As we will explain, the method does not require any manual assessment, thus providing a systematic approach to prioritize and therefore afterwards to evaluate the most promising spare parts first. 
The ranking method is based on information easily retrievable from company databases that describe the spare part characteristics and give insights about the value of printing these parts. For instance, in line with the explanations in the previous sections, a high demand rate may indicate that conventional manufacturing methods are a good fit and AM is less likely to be interesting. On the other hand, if the demand rate is low, it might be worthwhile to assess the potential benefit of producing the spare part with AM. Furthermore, we take into account company goals that give insight about how AM offers the highest value to the specific business. That is, companies focusing on cost reductions may profit differently from AM than companies having a strong quality focus. As listed below, the method consist out of four steps that we will describe in the next subsections.

1. Determining the spare part assortment to be investigated

2. Assigning a score to each spare part attribute, based on a comparison with the same attributes of other spare parts (horizontal comparison)

3. Assigning weights to spare part attributes, specifying the degree to which these attributes contribute to overall company goals (vertical comparison)

4. Determining a weighted score for each part

For a more elaborate discussion of the methodology, we refer to Knofius et al. (2016).

\section{Determining the spare part assortment to be investigated}

To determine what spare parts in principle might be eligible to be produced by AM, we need to specify what are major determinants. To that end, we characterize each part by two physical and eight operational attributes, as specified in Table 28.1.

\begin{tabular}{|l|l|}
\hline Parts charactization by attributes \\
\hline \multirow{5}{*}{ Physical attributes } & Material type (electronic, metal, plastic) \\
\cline { 2 - 3 } & Part size $\left(\mathrm{dm}^{3}\right)$ \\
\hline \multirow{5}{*}{ Operational attributes } & Demand rate (estimated number of requests per month) \\
\cline { 2 - 3 } & Resupply lead time (in months) \\
\cline { 2 - 2 } & Agreed response time (in months) \\
\cline { 2 - 2 } & Remaining usage period (in months) \\
\cline { 2 - 2 } & Manufacturing/ order costs (in units of EURO 10.000,-) \\
\cline { 2 - 2 } & Safety stock costs (based on 2\% of manufacturing costs, per month) \\
\cline { 2 - 2 } & Number of supply options (number of potential suppliers) \\
\cline { 2 - 2 } & Supply risk (probability of supply discontinuation in the next year) \\
\hline
\end{tabular}

Table 28.1. Spare parts characterized by Physical and Operational Attributes

Note that the attribute agreed response time refers to the maximum time between receipt of a customer request for a part and the supply of a ready-for-use part at the customer site. The attribute remaining usage period describes the estimated time horizon the assets, where the spare part is used for, is still used/supported by the company. Finally, the attribute supply risk describes the likelihood that supply for the spare part is discontinued in the near future. As exemplified later supply risk is measurable with methods as for instance proposed by Jaarsveld \& Dekker (2011).

Empirically, the ten attributes proved to be suitable and often retrievable form company data. It needs to be noted however, that occasionally not exactly the information is available but instead some sort of substitute. Also, it may occur that information for different spare part groups may reside with different partners (OEM's, asset owners, service providers). Depending on the records for each spare part group, it may become necessary to separate the analysis in order to maintain the comparability between all spare parts. Similarly, if for certain spare parts significantly less information is available compared to the overall population, it may appear necessary to exclude them from the 
analysis. Consequently, we usually end up with a subset of the entire spare part population. In Table 28.2, we present a snapshot of the resulting assortment list.

\begin{tabular}{|c|c|c|c|c|}
\hline Part ID & 1 & 2 & 3 & .................. \\
\hline Material (Electronic, Metal, Plastic) & E & M & $\mathrm{P}$ & ……............... \\
\hline Part size $\left(\mathrm{dm}^{3}\right)$ & 1 & 3 & 4 & ..................... \\
\hline Remaining usage period (in months) & 21 & 56 & 12 & ..................... \\
\hline Manufacturing/ order costs & 5 & 15 & 1 & ..................... \\
\hline Number of supply options & 1 & 14 & 3 & .................... \\
\hline Supply risk & 0.21 & 0.50 & 0.35 & .................... \\
\hline .............. & $\ldots \ldots$ & $\ldots \ldots .$. & .......... & ……….......... \\
\hline
\end{tabular}

Table 28.2. Details of Assortment Output List

\section{Assigning scores to spare part attributes}

For the physical attributes, a binary score (0-1) is applied, indicating whether or not a physical attribute value allows for AM anyhow, based on technological feasibility. Hence, a zero score on any physical attribute rules out the particular spare part for further investigation. For instance, based on current technology standards, a part size exceeding $125 \mathrm{dm}^{3}$ is rather unlikely to be economically printable; the same holds for electronics. Nevertheless, we would like to take this opportunity to emphasize that if both physical attributes are evaluated to 1 , it does not guarantee technological feasibility. It merely increases the probability of technological feasibility within the ranking. Later, after the ranking has been generated, an in-depth study of part attributes, not as easy to retrievable as material and part size, is necessary to draw a final conclusion about the technological feasibility.

For the operational attributes, we translate the value of each attribute into a linear score, ranging from 0 to 1 (needed since the operational attributes are defined in various dimensions). The part attribute score indicates how a part scores with respect to the economic potential of AM, when compared to other parts on solely this particular attribute. Hence, a score of 1 on a particular part attribute means that this part scores better (or not worse) than any other part on this particular attribute. A score of 0 means that all other parts score better on this particular attribute.

\section{Assigning weights to attributes}

For the assignment of weights to part attributes, the primary consideration is based on how the improvement of a part's attribute contributes to an improvement of operational performance, or even more, to strategic company goals. Regarding the latter, a common distinction is often made between companies focusing on costs reduction and companies focusing on operational improvements, while sometimes a third consideration concerns resilience against possible disruptions (see e.g. Chopra and Meindl, 2016, for a similar classification). In the context of spare parts management, we have defined improvements of three cost-related criteria, three operational performance criteria and one resilience-related criterion, see Table 28.3. In this table, we also indicated what a change of a particular part attribute might mean in terms of these criteria improvements, and hence, what it would contribute to the overall company goal. The table should be read as follows: if a particular attribute $x$ (left column) takes the relative value $y$ (central area), then the alternative of producing the part with AM might help to improve on criterion $z$ (upper row). As an example: if the resupply lead time of an existing part is long, then the alternative of AM might help to reduce safety stocks, improve the responsiveness of the supply chain, may add to the possibility to postpone customized production and finally also support the application of a temporary fix. For a more extensive justification of the impact of changing a certain spare part attribute we refer to Knofius et al. (2016). 


\begin{tabular}{|c|c|c|c|c|c|c|c|c|}
\hline & & \multicolumn{7}{|c|}{ Improvement potential } \\
\hline & & $\begin{array}{c}\text { Reduce } \\
\text { manufacturing/ } \\
\text { order costs }\end{array}$ & $\begin{array}{l}\text { Reduce direct } \\
\text { part usage } \\
\text { costs }\end{array}$ & $\begin{array}{l}\text { Reduce safety } \\
\text { stock costs }\end{array}$ & $\begin{array}{l}\text { Improve supply } \\
\text { chain } \\
\text { responsiveness }\end{array}$ & $\begin{array}{c}\text { Post- } \\
\text { ponement }\end{array}$ & $\begin{array}{c}\text { Temporary } \\
\text { fix }\end{array}$ & $\begin{array}{c}\text { Reduce } \\
\text { effect of } \\
\text { supply } \\
\text { disruptions } \\
\end{array}$ \\
\hline \multirow{8}{*}{ 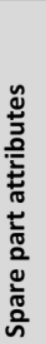 } & Demand rate & Low & & Low & & Low & & \\
\hline & Resupply lead time & & & Long & Long & Long & Long & \\
\hline & Agreed response time & & & Short & Short & & Short & \\
\hline & Remaining usage period & & Long & & & & & \\
\hline & Manufacturing/ order costs & High & & & & & & \\
\hline & Safety stock costs & & & High & & High & & \\
\hline & Number of supply options & Few & & & Few & & & Few \\
\hline & Supply risk & & & & High & & & High \\
\hline
\end{tabular}

= Costs reduction $\square=$ Operational improvement $\square=$ Supply Risk reduction

Table 28.3. Value range of spare part attributes that indicate improvement potential when switching to 3D printing.

In general, of course, a company will almost never entirely classify as cost-driven or operations-driven or resiliencedriven, so it is important to assign weights to each of these three company objectives (see the colors in Table 28.3). To this end, we apply the Analytical Hierarchy Process (AHP) in two subsequent stages (AHP, cf. Saaty, 2008). In the first stage, company representatives compare any two company goals, resulting in an overall weight of each of the three company goals (weighs sum up to one, hence each weight indicates the relative importance of the associated goal). Due to the pairwise comparison, inconsistency becomes controllable and decision complexity is prevented. From a small aggregation of Table 28.3, we learn that seven attributes relate to potential cost reductions, six to potential operational improvement, and two to supply risk reduction. Note that the two physical attributes are not related to any company goal. They concern technological feasibility of AM and hence are independent of these goals.

In the second stage of the AHP process, pairwise comparisons between any two assigned spare part attributes are made by company representatives again, resulting in a relative importance of each attribute in contributing to each company goal when switching to AM. The partial weight (partial, since it relates to a specific company goal) is now determined by multiplying the relative importance of each company goal with the relative importance of each attribute related to that company goal. Figure 28.7 presents a simplified example of the calculation, based on the four attributes listed in Table 28.2.

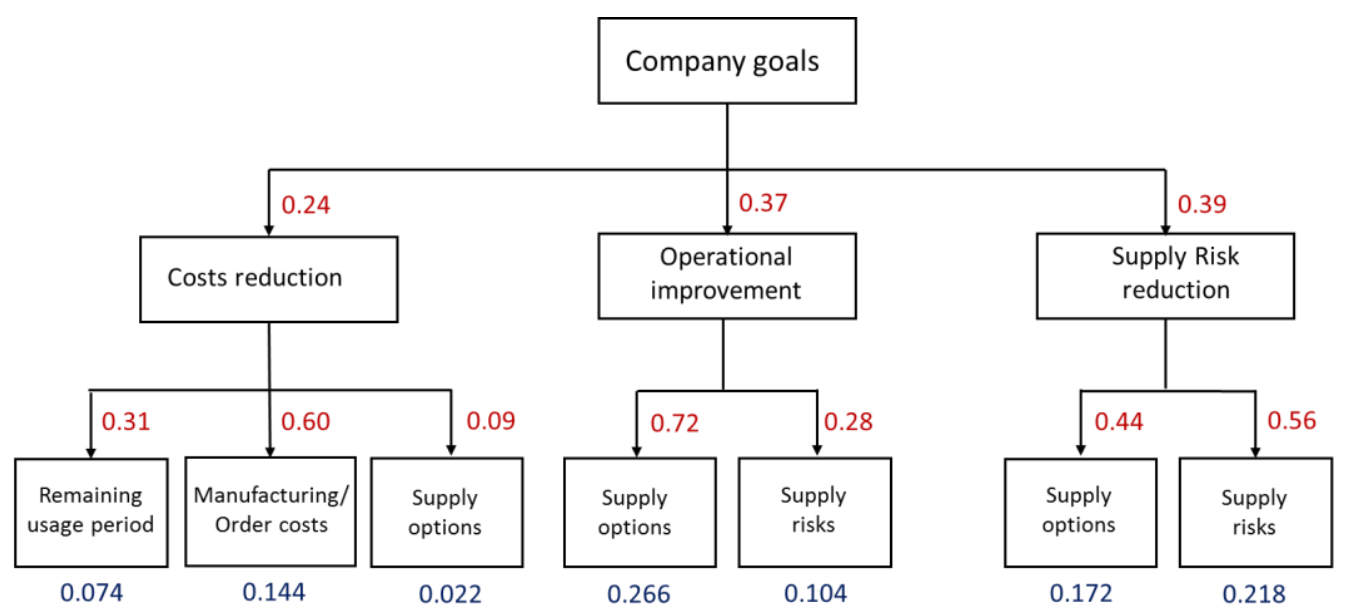

Figure 28.7. Calculation of partial weights of four attributes (blue digits) 
Finally, the weight of an attribute is obtained by summing up its partial weights. For example: the weight of attribute Supply risks is equal to $0.104+0.218=0.322$. It is important to realize that the attribute weights just indicate the relative importance of each attribute to the overall company goals when switching to AM.

\section{Determining a weighted score for each spare part}

Based upon the part attributes scores and the weights of the attributes, we are finally able to calculate a total score for each spare part, using the following calculation scheme.

For each part,

a. Determine a weighted score per operational attribute, by multiplying the weight with the score.

b. Multiply the scores of the physical attributes, called PAS, which results in either a 0 or a 1.

c. Determine the sum of the weighted scores of the operational attributes, called OAS.

d. Multiply PAS with OAS to determine the overall score of the spare part.

Note that if only one physical attribute has a score of zero, the overall parts score is zero as well (AM of this part appears technological infeasible). Table 28.4 provides an example of the calculation, based on the four operational attributes used in Table 28.2 and Figure 28.4.

\begin{tabular}{|l|l|l|l|l|}
\hline Attribute & Value & Weight & Score & Weighted score \\
\hline Material type & Metal & - & 1 & 1 \\
\hline Part size & 0.5 & - & 1 & 1 \\
\hline Supply risk & 20 & 0.322 & 0.21 & 0.06762 \\
\hline Remaining usage period & 15 & 0.074 & 0.31 & 0.02294 \\
\hline Supply options & 5 & 0.460 & 0.48 & 0.2208 \\
\hline Manufacturing/order costs & 48 & 0.144 & 0.24 & 0.03456 \\
\hline & \multicolumn{5}{r}{ Overall score } & $\mathbf{0 . 3 4 5 9 2}$ \\
\hline
\end{tabular}

Table 28.4. Calculating the overall parts score as a candidate for additive manufacturing

This concludes the description of the spare parts ranking procedure. Based on the resulting ranking, the analysis would proceed with a manual assessment starting from the best scoring part. In that way, it is more certain that most promising spare parts are assessed first and the risk of disregarding interesting parts is minimized. In the following case study, we show how the method proved its value in spare parts management in the aviation industry.

\subsubsection{Case Study: Selecting spare parts for AM in the aviation industry}

The selection procedure presented in the preceding section has been tested during a field study at a part supplier in the aviation industry, with more than 400,000 spare parts. After an evaluation of the data availability and data cleaning, we decided together with company representatives to base the analysis on 40.330 spare parts. Additionally, this selection ensured design ownership and excluded confidential parts.

As basis for the analysis, we used the two physical and eight operational attributes as specified in Section 28.3.1. Given that we did not find a suitable data source for the agreed response time, we had to drop this attribute. Furthermore, we used the part number as a substitute for the part size, because direct information about the part 
size was often not accessible with data base queries. Fortunately, the company-specific numbering system relates part size to the part number and thus turned out to be a good proxy.

In addition, we used the attribute airplane type instead of number of supply options. The reason was that for spare parts that are exclusively used in a specific airplane type, demand is fulfilled by dismantling phased-out airplanes. Other information about the number of supply options was not easily retrievable.

Finally, we substituted supply risk by the attribute survival probability where the survival probability defines the chance that a spare part supplier will be available within one year. This measure appeared to be available in this company for most analyzed spare parts and was computed based on the method of Jaarsveld \& Dekker (2011). In Table 28.5, we present an overview of all used attributes associated with the weights derived from the AHP method.

\begin{tabular}{lll}
\hline Attribute & Weight & Explanation \\
\hline Part number & - & The part number gives insights about spare part size \\
Material type & - & Indicates the material type e.g. electronic, composite or metal \\
\hline Safety stock costs & 0.18 & High safety stock may be reduced with AM \\
Manufacturing/order costs & 0.17 & High sourcing costs may be reduced with AM technology \\
Demand rate & 0.16 & For low volume production AM may reduce order costs \\
Survival probability & 0.13 & Spare parts with high supply risk could be obtained with AM \\
Remaining usage period & 0.13 & An early lifecycle phase may indicate high saving potentials of operational costs \\
Resupply lead time & 0.13 & AM may reduce long resupply lead time and thus decrease safety stocks \\
Airplane type & 0.10 & Specific airplanes obtain less spare parts from dismantling \\
\hline \hline
\end{tabular}

Table 28.5. Attributes and weights used in the aviation spare parts study

During the analysis, we found that 34.140 spare parts did not pass one of the physical attribute tests, hence were not feasible to print from a technological perspective (at least with the current state of technology). The remaining 6.190 spare parts were ranked, which resulted in a score distribution as shown in Figure 28.8.

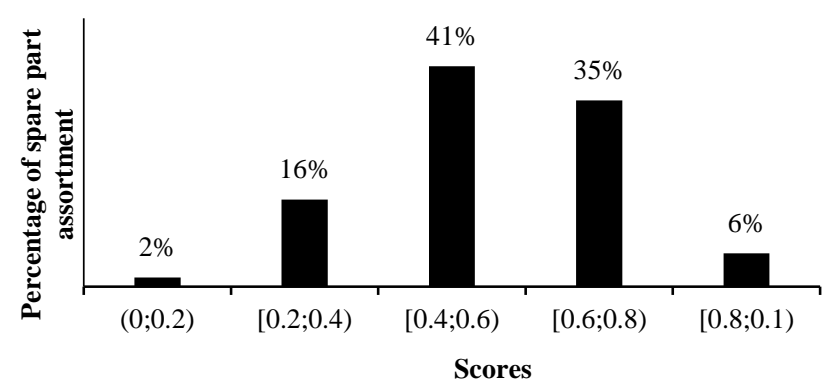

Figure 28.8. Score distribution of parts in aviation field study 
Based on the ranking, the case company could already identify 1,141 technologically feasible and economically beneficial business cases. Today, only the non-formalized certification process holdback the change-over to AM for some safety-critical parts. In the near future however, this is expected to change. A typical example is a fitting stud used for the attachment of a safety belt as illustrated in Figure 28.9. For this case, it is estimated that the resupply lead time might be reduced by some 40 percent and the order costs by about 70 percent with AM. The prospect of this improvement potential stimulated a reengineering project for the fitting stud despite high efforts for certification. This outcome demonstrates the benefit of the developed top-down approach: practitioners probably would have disregarded the fitting stud due to its high certification effort. In comparison, the ranking method typically exposes promising characteristics for high-scoring items and thus justifies an assessment of the part in more detail.

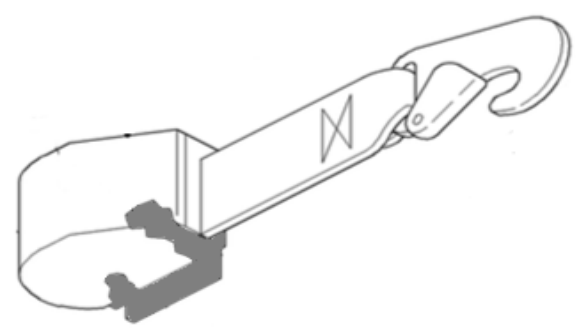

Figure 28.9. Safety belt with fitting stud (grey)

\subsection{Further Reading}

A good introduction in the development of AM technologies and their strategic impact is given in the Additive Manufacturing Strategic Research Agenda 2014, cf. AM Platform (2014) and in Deloitte (2013), see also Wohlers (2012) and subsequent reports of the Wohlers Association. An introduction in AM technologies is provided by Gibson et al. (2010). The scientific literature on AM and more in particular on its impact on the supply chain is still relatively young, see e.g. Thomas (2015), Khajavi et al. (2014), Sasson and Johnson (2016), Oettmeier and Hofmann (2016) and Walter et al. (2014). Sirichakwal and Conner (2016) and Holmström et al. (2010) discuss the impact of AM on spare parts inventories in the supply chain. Parts selection is discussed by the current authors in Knofius et al. (2016). Consolidation aspects of additive manufacturing are discussed in Yang et al. (2015) and Knofius et al. (2016a).

\section{References}

AM Platform (2014). Additive Manufacturing: Strategic Research Agenda 2014

Andersson O, Graichen A, Brodin H, Navrotsky V. (2016). Developing Additive Manufacturing Technology for Burner Repair. ASME. J. Eng. Gas Turbines Power.139(3):031506-031506-9. doi:10.1115/1.4034235.

Behfard, S., van der Heijden, M., Al Hanbali, A and Zijm, W.H.M. (2015). Last time buy and repair decisions for spare parts. European Journal of Operational Research, 498-510

Chopra, S., \& Meindl, P. (2016). Supply Chain Management: Strategy, Planning and Operation 6th Edition. Essex: Pearson Education Limited

D’Aveni, R. (2015). The 3-D Printing Revolution. Harvard Business Review, May 2015 (https://hbr.org/2015/05/the3-d-printing-revolution)

Deloitte (2014). 3D opportunity in areospace and defense: Additive manufacturing takes flight. Deloitte University Press 
EOS (2015). Additive Manufacturing, Laser-Sintering and industrial 3D printing - Benefits and Functional Principle. url: https://www.eos.info/additive manufacturing/for technology interested

EPRS (2014). Reshoring of EU manufacturing, Briefing to the EU Parliament by the European Parliamentary Research Service 21/03/2014

Ford (2017). Ford Tests Large-Scale 3D Printing with Light-Weighting and Personalization in Mind. url: https://media.ford.com/content/fordmedia/fna/us/en/news/2017/03/06/ford-tests-large-scale-3d-printing.html (visited on 03/07/2017).

Gibson, I., Rosen, D., \& Stucker, B. (2015). Additive Manufacturing Technologies: 3D Printing, Rapid Prototyping and Direct Digital Manufacturing, $2^{\text {nd }}$ ed. Springer Verlag, New York

Holmström, J., Partanen, J., Tuomi, J. \& Walter, M., (2010). Rapid manufacturing in the spare parts supply chain: Alternative approaches to capacity deployment. Journal of Manufacturing Technology Management, 21(6), pp. 687-697

Jaarsveld \& Dekker (2011). On the use of installed base information for spare parts logistics: A review of ideas and industry practice. International Journal of Production Economics, 143(2), pp/ 536-545

Kalpakjian S (1992). Manufacturing engineering and technology, 2nd edn. Addison-Wesley, Reading, MA

Khajavi, S., Partanen, J. \& Holmström, J., 2014. Additive manufacturing in the spare parts supply chain. Computers in Industry, 65(1), pp. 50-63

Knofius, N., van der Heijden, M.C. and Zijm, W.H.M. (2016). Selecting parts for additive manufacturing in service logistics, Journal of Manufacturing Technology Management, Vol. 27 No. 7, pp. 915-931

Knofius, N., van der Heijden, M.C. and Zijm, W.H.M. (2016a). Consolidating spare parts for asset maintenance with additive manufacturing, Research Report, University of Twente (submitted for publication)

Knofius, N., van der Heijden, M.C., Sleptchenko, A. and Zijm, W.H.M. (2017). Improving effectiveness of spare part supply by additive manufacturing as dual sourcing option, Research Report, University of Twente (submitted for publication)

McCue, T.J. (2015). 3D printing is Changing the Way We Think. Harvard Business Review, July 2015 (https://hbr.org/2015/07/3d-printing-is-changing-the-way-we-think\&cm sp=Article- -Links- Top\%20of\%20Page\%20Recirculation)

Oettmeier, K. and Hofmann, E. (2016). Impact of additive manufacturing technology adoption on supply chain management processes and components, Journal of Manufacturing Technology Management, Vol. 27 No. 7, pp. 944-968

Renishaw (2016). Metal additive manufacturing technology used for customised mountain bikes. url: http://www.renishaw. nl/nl/metal-additive-manufacturing-technology-used-for-customised-mountain-bikes--39741

Saaty, T. (2008). Decision making with the analytic hierarchy process. Int. J. Services Sciences, Vol. 1, No. 1, 83-98 Sasson, A. \& Johnson, J., 2016. The 3D printing order: variability, supercenters and supply chain reconfigurations. International Journal of Physical Distribution \& Logistics Management, 46(1), pp. 82-94 
Siemens (2014). Additive Manufacturing: 3D Printing: Facts \& Forecasts. url:

https://www.siemens.com/innovation/en/home/pictures-of-the-future/industry-and-automation/Additive-

manufacturing-facts-and-forecasts.html (visited on 03/07/2017).

Siemens (2014a). Additive Manufacturing: From Powders to Finished Products. url:

https://www.siemens.com/innovation/en/home/pictures-of-the-future/industry-and-automation/additive-

manufacturing-from-powders-to-finished-products.html (visited on 03/07/2017).

Sirichakwal, I. \& Conner, B., 2016. Implications of Additive Manufacturing for Spare Parts Inventory. 3D Printing and

Additive Manufacturing, 3(1), pp. 56-63

TechCrunch (2016). NASA is sending a 3D printer to space that you can use, retrieved from

https://techcrunch.com/2016/03/19/nasa-is-sending-a-3d-printer-to-space-that-you-can-use/

Thomas, D., 2016. Costs, benefits, and adoption of additive manufacturing: a supply chain perspective.

International Journal of Advanced Manufacturing Technology Volume 85, Issue 5, pp 1857-1876

Van der Heijden, M., Alvarez, E. and Schutten, J. (2013). Inventory reduction in spare part networks by selective throughput time reduction, International Journal of Production Economics, Vol. 143 No. 2, pp. 509-517

Walter, M., Holström, J., \& Yijölä, H. (2004). Rapid manufacturing and its impact on supply chain management. Logistics Research Network Annual Conference. Dublin

Wohlers (2012). Additive Manufacturing and 3-D Printing State of the Industry, Annual Worldwide Progress Report (2012 ed.), Wohlers Associates, Colorado, USA

Yang, S., Tang, Y. \& Zhao, Y., 2015. A new part consolidation method to embrace the design freedom of additive manufacturing. Journal of Manufacturing Processes, 20(3), pp. 444-449 